\title{
Longitudinal variations in planetary wave activity in the equatorial mesosphere
}

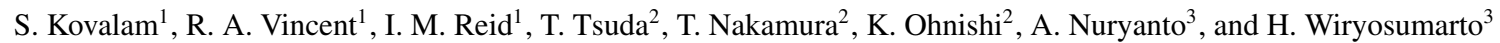 \\ ${ }^{1}$ Department of Physics and Mathematical Physics, University of Adelaide, Adelaide, Australia \\ ${ }^{2}$ Radio Atmospheric Science Center, Kyoto University, Kyoto, Japan \\ ${ }^{3}$ Indonesian Institute for Aeronautics and Space, Jakarta, Indonesia
}

(Received August 17, 1998; Revised March 19, 1999; Accepted March 19, 1999)

\begin{abstract}
Zonal and meridional winds in the equatorial mesosphere and lower thermosphere $(65-98 \mathrm{~km})$ measured at two sites separated by $94^{\circ}$ in longitude are used to study the zonal structure of planetary-scale waves. The data were obtained with MF radars located at Pontianak $\left(0^{\circ} \mathrm{N}, 109^{\circ} \mathrm{E}\right)$ and Christmas Island $\left(2^{\circ} \mathrm{N}, 157^{\circ} \mathrm{W}\right)$. The data at Christmas Island were collected from January 1990 to December 1997 and the observations at Pontianak were made from November 1995 to July 1997. Power spectral techniques are used to study the amplitude and frequency variations of long-period oscillations as a function of height and time. A mean climatology of these variations taken from years 1990-1997 is presented. Strong peaks in zonal and meridional winds are found at tidal periods and for the quasi 2-day wave. Zonal spectra exhibit considerable power at periods of 3-10 days, with transient oscillations with periods near 3.5 day and 6.5 days being especially prominent. The 6.5 -day wave is particularly strong during April and September. Examination of the phase differences obtained from cross-spectra between the two stations show that the 6.5-day wave is westward propagating with zonal wavenumber 1 , while the 3.5 day wave is eastward propagating with wavenumber 1 . The 6.5-day wave is identified as a manifestation of an unstable mode, while the 3.5-day wave is identified as an ultrafast Kelvin wave. There are significant longitudinal variations in the amplitudes and inferred momentum fluxes of the 3.5-day wave, amplitudes being larger in the Asian region than in the central Pacific.
\end{abstract}

\section{Introduction}

It is believed that the zonal-mean zonal circulation of the equatorial middle atmosphere is driven primarily by waves propagating up from the troposphere. Wave driving is thought to be especially important in producing the semiannual oscillations (SAO) in the zonal-mean zonal winds that occur in the altitude range $30-90 \mathrm{~km}$ over the equator. The largest amplitudes of the SAO $\left(\sim 30 \mathrm{~m} \mathrm{~s}^{-1}\right)$ occur near the mesopause $(\sim 85 \mathrm{~km})$ and the stratopause $(\sim 50 \mathrm{~km})$, with very small amplitudes near $65 \mathrm{~km}$ (Hirota, 1978; Hamilton, 1982; Garcia et al., 1997). Several mechanisms are likely to be responsible and this has motivated studies to distinguish the ways in which the mesopause and the stratopause SAO are driven (e.g. Dunkerton, 1982).

Understanding of the dynamics of the equatorial mesosphere and lower thermosphere (MLT) region has improved markedly in the last decade. Radar probing of equatorial mesosphere became possible with the installation of a meteor scatter radar (Avery et al., 1990) and a separate MF radar (Vincent and Lesicar, 1991) on Christmas Island $\left(2^{\circ} \mathrm{N}\right.$, $157^{\circ} \mathrm{W}$ ) in the central Pacific. Investigations of the equatorial MLT in the western Pacific started with the installation of a meteor wind radar at Jakarta $\left(6^{\circ} \mathrm{S}, 107^{\circ} \mathrm{E}\right)$ (Tsuda et al., 1995). Recently, equatorial middle atmosphere wind measurements from the Upper Atmospheric Research Satellite (UARS) have become available. The combination of

Copy right(c) The Society of Geomagnetism and Earth, Planetary and Space Sciences (SGEPSS); The Seismological Society of Japan; The Volcanological Society of Japan; The Geodetic Society of Japan; The Japanese Society for Planetary Sciences. ground-based and UARS observations provide a detailed climatological picture of the mean circulation (Lieberman et al., 1993; Palo and Avery, 1993; Vincent, 1993; Burrage et al., 1996b; Garcia et al., 1997), equatorial waves (Canziani et al., 1995; Lieberman and Riggin, 1997; Riggin et al., 1997), normal modes (Harris and Vincent, 1993; Wu et al., 1993; Palo and Avery, 1996), tides (McLandress et al., 1996; Vincent et al., 1998), and gravity waves (Conner and Avery, 1996; Isler and Fritts, 1996).

This paper uses data from the Christmas Island radar and from an MF radar recently installed at Pontianak $\left(0^{\circ} \mathrm{N}\right.$, $109^{\circ} \mathrm{E}$ ) in Indonesia. Pontianak is situated in the convectively active Maritime Continent region of the Western Pacific while Christmas Island is situated in a usually convectively quiescent region. The characteristics of equatorial waves change as they propagate away from their source regions in the troposphere (Liebmann and Hendon, 1990), so the radars are ideally located for investigating longitudinal variability in the mesosphere. Combining the data from different sites can also provide information on the zonal wave number.

In this paper we investigate the characteristics of the long period waves as a function of both longitude and height. The data collection and analysis procedures are described in Sections 2 and 3 and the results, including estimates of zonal wavenumber, are discussed in Section 4 . The results are summarized and further discussed in terms of possible wave types in Section 5. 


\section{Data Collection and Analysis}

The MF radars used in this study are identical in construction and operating frequency $(1.98 \mathrm{MHz})$, with winds measured using the spaced-antenna technique. Raw data are analyzed in realtime using the full correlation analysis (Briggs, 1984). The commonality of the radars and data analysis techniques minimizes any problems that sometimes occur when data obtained with different techniques are compared. Observations are taken over the altitude range 60 to 98 $\mathrm{km}$, with measurements made at $2 \mathrm{~km}$ height intervals every 2 minutes. The actual height coverage and time resolution obtained depends on the presence of suitable irregularities for scattering the radiowaves from the lower ionosphere.

Wind measurements are available from Christmas Island for the period January 1990 to December 1997. The observations at Pontianak started in November 1995 and are available up to August 1997. These data provide us with nearly continuous data set of zonal and meridional winds in the height range $78-98 \mathrm{~km}$ both day and night. The data were screened to remove outliers and time series formed from hourly averages were used since we are here interested only in long-period motions.

\section{Analysis Procedures}

The analysis of the radar wind data was separated into two categories. (i) Background wind studies to examine the seasonal behavior of the mesospheric flow and, (ii) studies of the energy content of the long-period waves in the mesosphere.

We begin by spectrally analysing the velocity time series of Christmas Island and Pontianak at each height. Short gaps in the time series were filled by linear interpolation and conventional FFT techniques applied after the subtraction of a linear trend. The power spectral densities provide information about the spectral content of the signal at a fixed point of time. Moving time window spectra were used to study the temporal behavior of mesospheric waves. Power spectra were computed for a short time segment or window of data and the window was then shifted by an appropriate time step and the power spectra recalculated. By continuing this process a description of the spectral behavior with time was acquired.

The moving window analyses showed that mesospheric wave activity was highly dynamic, with significant changes in spectral power occurring in relatively short time intervals. The data were reanalyzed using harmonic fits in order to obtain more quantitative estimates of wave amplitudes and phases at times when the spectral powers were large. A linear trend was removed from the data and a least-squares harmonic fit made using a singular value decomposition technique (Press et al., 1992). The harmonic fitting window spanned at least four cycles of a wave period. The window was then advanced by an appropriate amount to obtain the time dependence of amplitude and phase.

\section{Analysis Results}

\subsection{Mean zonal winds}

The focus of this paper is on seasonal and longitudinal variations in planetary wave activity, but to set the results in context we first consider the behavior of the prevailing winds. Figure 1 shows time series of the mean zonal winds measured

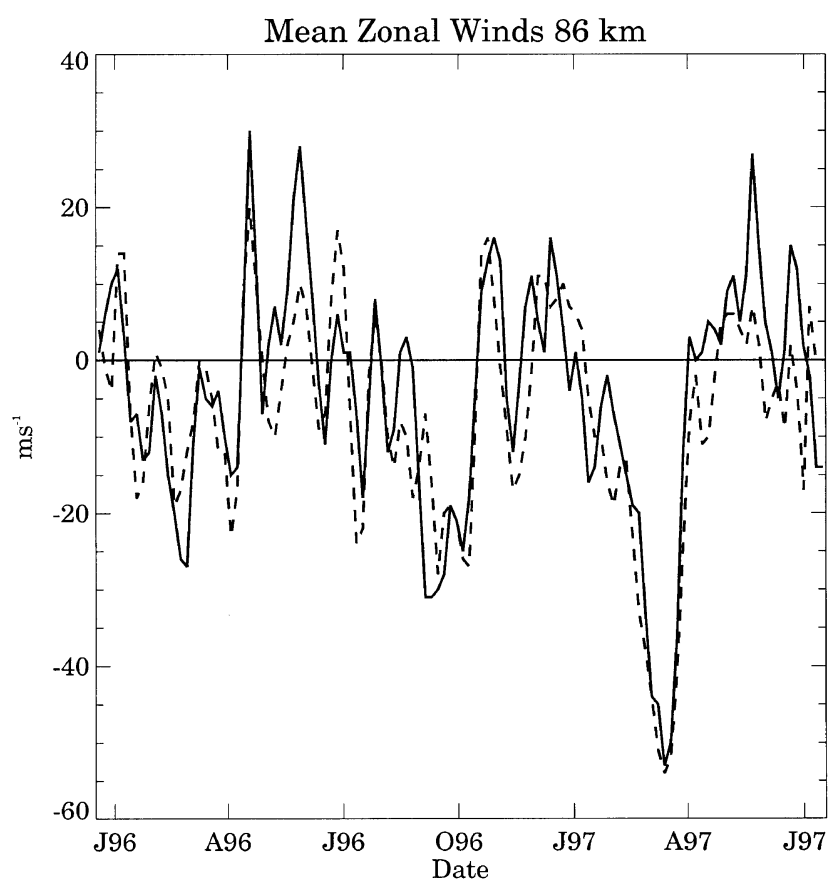

Fig. 1. Mean zonal winds in 10-day intervals at $86 \mathrm{~km}$ for Christmas Island (solid) and Pontianak (dashed)

at Christmas Island and Pontianak at an altitude of $86 \mathrm{~km}$, where the seasonal variations in the zonal wind tend to be largest (Vincent, 1993; Garcia et al., 1997). The mean winds were derived from 10-day windows that were advanced in 5 day steps. It is apparent that the winds at each site track each other very closely. The mesospheric semiannual oscillation (MSAO) is very apparent, with negative (westward) flow at the equinoxes and positive (eastward) flow at the solstices. Strong interannual variability is also apparent, with the westward flow in March/April 1997 much stronger than in March/April 1996. This pattern of weak and strong zonal westward winds in March/April in alternate years continues the sequence reported by Burrage et al. (1996b) and Garcia et al. (1997) who noted an apparent correlation between the westward phase of the MSAO and the quasi-biennial oscillation in zonal-mean zonal winds in the stratosphere.

It is noteworthy that wind fluctuations on time scales shorter than seasonal are also very similar at Pontianak and Christmas Island. These fluctuations with periods of tens of days are manifestations of mesospheric intraseasonal oscillations first reported by Eckermann and Vincent (1994) and Eckermann et al. (1997) from observations at Christmas Island. The strong similarity of the intraseasonal variations at the two sites indicate that they are global in extent, reinforcing the findings of Lieberman (1998).

\subsection{Power spectra}

Figure 2 shows the mean spectra of the zonal and the meridional winds derived from the nineteen months of simultaneous data obtained at Christmas Island and Pontianak. The spectrum for each wind component was constructed by subdividing the time series into 40-day segments and averaging the power spectra computed for each segment. The segments were overlapped by $50 \%$ in order to minimize the variance 

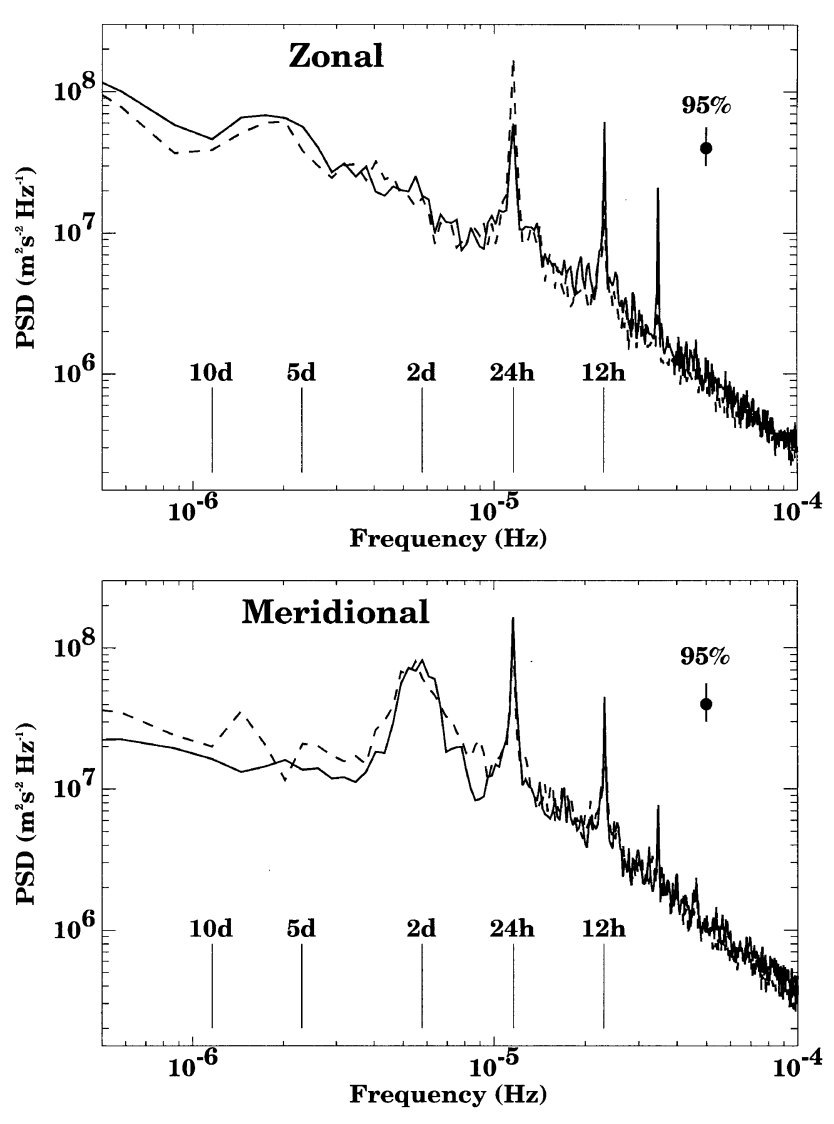

Fig. 2. Frequency spectra of hourly averaged zonal (top) and meridional winds (bottom) averaged between 86 and $92 \mathrm{~km}$ at Christmas Island (solid line) and Pontianak (dashed line) for the period November 1995 to August 1997. Confidence limits at the $95 \%$ level are indicated.

associated with each spectral estimate (Press et al., 1992). Spectra computed for four heights from 86 to $92 \mathrm{~km}$ were then averaged together to further improve the spectral reliability. At each height there were 29 overlapping segments giving a notional $29 \times 2 \times 9 / 11 \sim 47.5$ degrees of freedom (dof). The factor of $9 / 11$ arises from the correlation between overlapping segments (Press et al., 1992). Averaging over four height ranges $(8 \mathrm{~km})$ should increase the $d o f$ by a factor of 4 , but spectra from adjacent heights are not completely independent since the radar pulse length is about $4 \mathrm{~km}$. It is conservatively estimated that there are about 95 dof associated with each spectral estimate. Confidence limits at the $95 \%$ level are shown. Spectra for the full 8 years of data from Christmas Island (not shown) are very similar.

The spectra for a given wind component are very similar at the two sites, which indicates that similar dynamical processes are being observed. Narrow spectral peaks associated with the diurnal, semidiurnal and terdiurnal tides are clearly evident. However, the diurnal tidal amplitudes in the zonal component are larger at Pontianak than at Christmas Island. Conversely, the semidiurnal amplitudes are a little larger at Christmas Island. At periods shorter than about 1 day the spectral densities decrease with an approximate $f^{-5 / 3}$ power law as found at other latitudes. This part of the spectrum is usually ascribed to gravity wave motions (see Fritts and VanZandt (1993) and references therein). In the high fre- quency part of the spectrum energies are approximately equally partitioned between the zonal and meridional wind components. At periods longer then $24 \mathrm{~h}$, however, energy is less equally distributed. The broad peak with a period near two days in the meridional component is due to the quasi-2day wave, which is a strong feature of the midlatitude summer mesosphere, particularly in the southern hemisphere (Salby, 1981, 1984; Harris, 1993; Palo et al., 1997). The zonal spectra exhibit considerable power in the period range between 3 and 10 days, with a broad peak evident near 6 to 7 days.

To summarize seasonal variations in wave activity, Fig. 3 represents the annual average power spectral density of MLT wind components in the frequency range 0.1 to $0.6 \mathrm{cpd}$ at Christmas Island for the entire eight-year observing period. The power spectra were computed using time series that were 40 days in length (bandwidth of $0.025 \mathrm{cpd}$ ) which were then stepped forward one day at a time and the spectra recomputed. The spectral powers were limited or clipped to a maximum value of $4 \times 10^{8} \mathrm{~m}^{2} \mathrm{~s}^{-2} \mathrm{~Hz}^{-1}$ in order to bring out more clearly the details in the spectra and allow them to be compared on an equivalent basis. Maximum activity appears between January and April and between July and October in the zonal wind component. Strong peaks are especially apparent near $0.15 \mathrm{cpd}$ ( 6 to 7 day periods) in April and September. Relatively strong wave activity is also apparent at a frequencies of $0.33 \mathrm{cpd}$ ( 3 days) in August and near $0.28 \mathrm{cpd}$ ( 3.5 days) in early September. The dominant feature of the meridional wind plot is the quasi-2 day wave. This seems to be present almost continuously, but has maxima in January/February, March, July/August and in September/October. The behavior of the 2-day wave in the equatorial MLT will not be discussed further here, as it is similar to that extensively described by Harris and Vincent (1993) and Palo and Avery (1996) from Christmas Island observations.

Although Fig. 3 is an an average of eight years of observations it still suggests that wave activity is often transitory. Moving window power spectra were computed in order to investigate better the short term temporal behavior on both seasonal and interannual timescales. Figures 4 and 5 show the spectra of the zonal and the meridional wind at Christmas Island and Pontianak, respectively. Considerable transient power is observed at periods near 2-days $(f \sim 0.5 \mathrm{cpd})$ in the meridional wind component, but relatively little energy is observed in the zonal component at this frequency. As expected from the mean power spectra the zonal winds are dominated by transient wave activity in the frequency range $0.1-0.3 \mathrm{cpd}$. Bursts of activity at frequencies near $0.16 \mathrm{cpd}$, corresponding to a period of about 6 days, are particularly evident at both stations. More sporadic bursts of activity are also evident in the frequency range 0.25 to $0.33 \mathrm{cpd}$ (periods between 3 and 4 days).

Cross-spectra provide another way of exploring the relation between the dynamics at Pontianak and Christmas Island. Mean cross-spectra were computed in a similar manner to the mean power spectra, that is in overlapping 40day segments. The complex amplitudes were first averaged over all segments and then averaged over four heights before the cross-spectral amplitudes were computed. The nineteen-month average cross-spectra between Pontianak $(\mathrm{P})$ 

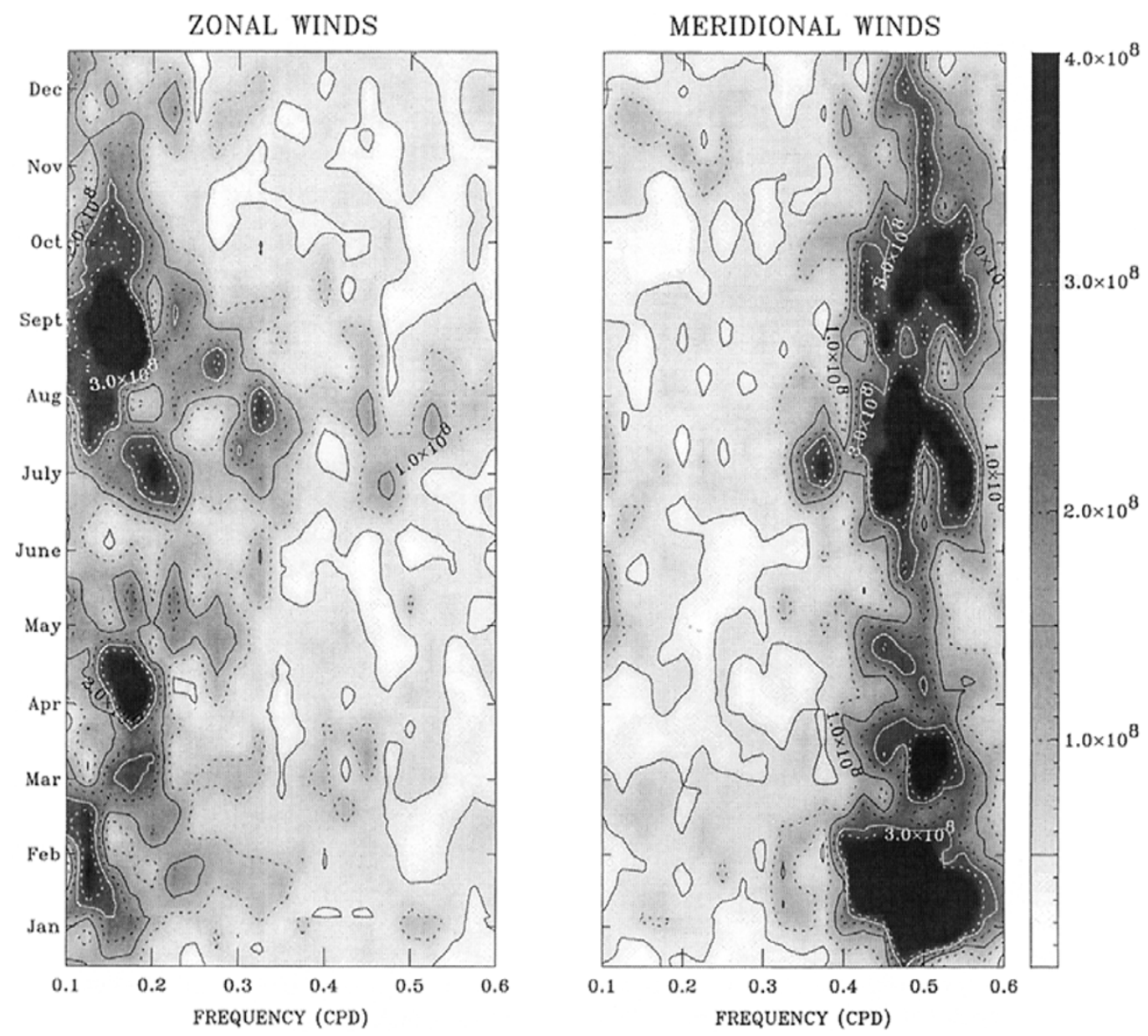

Fig. 3. Annual-average moving-window power spectra of zonal (left) and meridional (right) winds at Christmas Island. A 40-day window is used. The bar indicates spectral density in $\mathrm{m}^{2} \mathrm{~s}^{-2} \mathrm{~Hz}^{-1}$

and Christmas Island (C) are presented in Fig. 6 in terms of the squared-coherence $\left(\operatorname{coh}^{2}\right)$ and cross-spectral phase $(\phi)$ at frequency $f$, where

$$
\operatorname{coh}^{2}(f)=\frac{\overline{S_{P C}^{2}(f)}}{\overline{S_{P}^{2}}(f) \overline{S_{C}^{2}}(f)}
$$

and

$$
\phi(f)=\arctan \left(\mathcal{I}\left(\overline{S_{P C}}(f)\right) / \mathcal{R}\left(\overline{S_{P C}}(f)\right)\right) .
$$

Here $\mathcal{R}$ and $\mathcal{I}$ are the real and imaginary parts respectively, and the phase is such that a positive value means that Christmas Island leads Pontianak.

The results for the zonal component are shown in Fig. 6 for the period range from 1.1 to 10 days. The coherence-squared values are highly significant at periods near 6.5, 3.5, and 2.5 days. The phase plot shows that on average Christmas Island leads Pontianak by about 0.25 cycle at a period of 6.5 day, but at 3.5 day the phase difference is about -0.25 cycle. For reference, the dotted lines show the phase differences expected for waves with zonal wavenumber 1 propagating westward (+1) and eastward ( -1$)$. However, spatial aliasing means that similar phase differences would be observed for eastward and westward propagating zonal wavenumber-3 waves.

\subsection{Harmonic analysis}

The similarity of the transient fluctuations in power evident in Figs. 4 and 5 means that the same phenomena are being observed at the two locations so that they are global in scale. For example, in April 1996 a large burst of activity with a period near 6 days is evident in both plots in the zonal component. By comparing the individual wind oscillations of this event as a function of height and time it is possible to investigate both the vertical wavelength and horizontal direction of propagation. Time series of the zonal winds measured at three heights are displayed in Fig. 7. The data were bandpass filtered with a bandpass between 0.18 and $0.125 \mathrm{cpd}$ (periods between 5.5 and 8 days). The event lasted for about 4-5 oscillations ( $\sim 30$ days) and the very similar behavior at the two sites supports the idea of a globally propagating mode. There is a phase shift of approximately 1 day between 84 and $94 \mathrm{~km}$ implying that the vertical wavelength is about $65 \mathrm{~km}$, although comparisons over a larger height range are required to better estimate the wavelength. An important feature is that the oscillations at Christmas Island lead those at Pontianak by $\sim 90^{\circ}$. Given the $94^{\circ}$ station separation this suggests that the wave is westward propagating with a zonal wavenumber of one. As noted, however, spatial aliasing could mean that it is an eastward propagating wave 3. The latter possibility is an unlikely explanation for this 

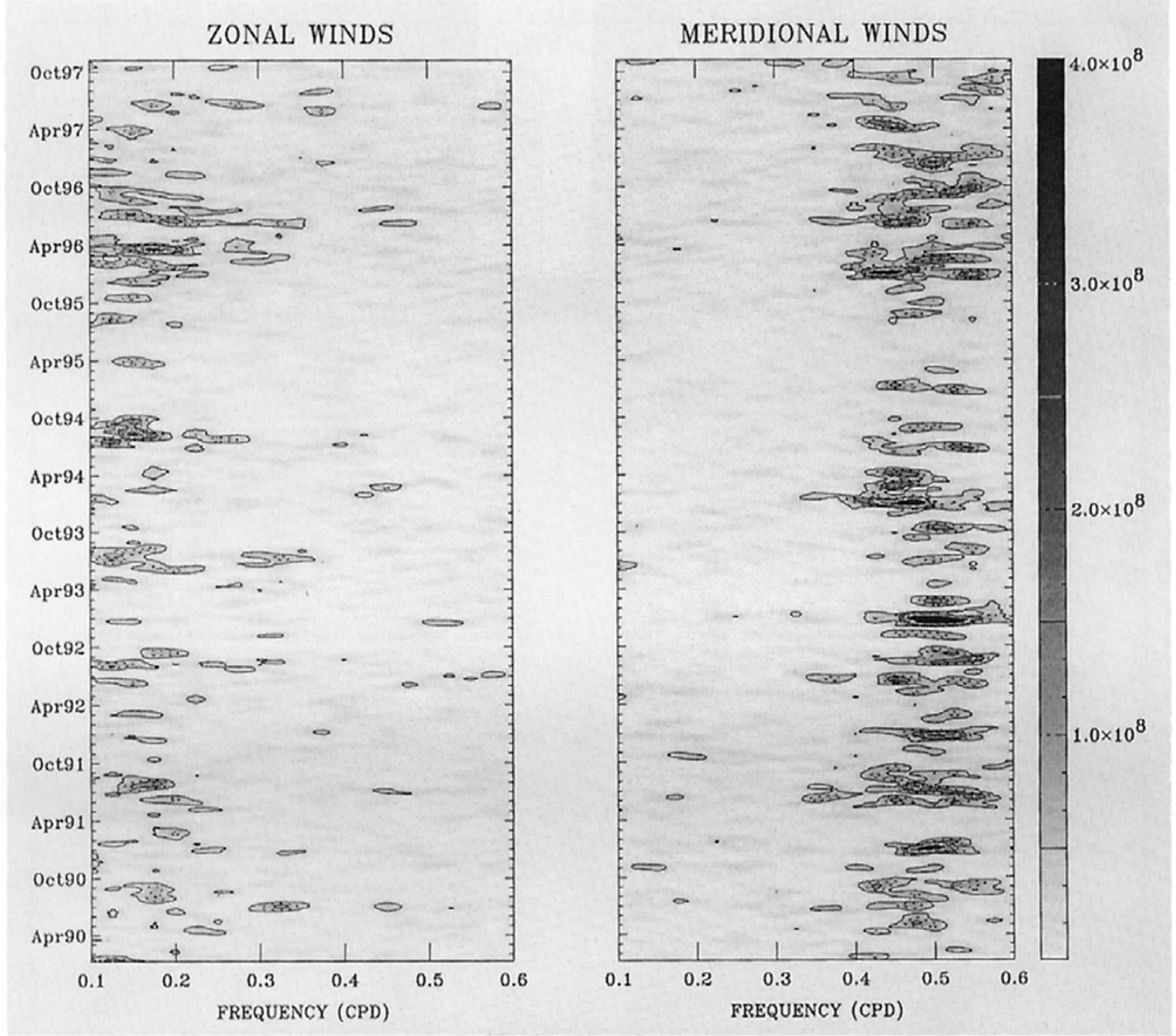

Fig. 4. Moving-window power spectra of zonal (left) and meridional (right) winds for Christmas Island for the period January 1990 to December 1997.

mode, as discussed in Subsection 5.1.

The details of the event described above typify the general behavior of the 6.5-day wave. To provide a more quantitative description of the activity as a function of height and time a harmonic analysis was carried out for calendar year 1996. The data were analyzed in thirty-day segments, with each segment moved on by 15 days. Time series of the amplitude and phases were generated at each height between 78 and 98 $\mathrm{km}$. Contour plots of the zonal amplitude at the two stations are given in Fig. 8. The phase, represented by the time of maximum eastward wind, are superimposed as solid circles.

Amplitudes are somewhat different at the two stations, but the overall seasonal behavior is similar. In the first half of the year maximum amplitudes are attained in April, and in the second half they are centered on September, although significant amplitudes are observed in July and October at Christmas Island. Thirty-day average amplitudes as large as $20 \mathrm{~m} \mathrm{~s}^{-1}$ are found near $90 \mathrm{~km}$, but short-term peak amplitudes are even larger (Fig. 7). It is interesting to note that zonal amplitudes show strong variations with height during March/April and September/October. Wave amplitudes maximize between 90 and $95 \mathrm{~km}$ and then slowly decrease with increasing in height. At other times the variation is irregular. These figures also show that phases are highly organized throughout the observation period and are similar at the two sites. Usually there is a downward progression with time, although upward phase progressions are sometimes observed, usually when the amplitudes are weak so that the phases are less reliably determined. The small change in phase with height is an indication of the long vertical wavelength of the 6.5-day wave.

The general properties of the 3.5-day wave were analyzed in a manner similar to that described above. Figure 9 illustrates the time-height variation of the zonal wave field of the 3-day wave at the Christmas Island and Pontianak for 1996. Table 1 summarizes the main features of the 3.5-day wave in two-month intervals. Variations in the wave period were studied by band-pass filtering the hourly average time series between 0.22 and $0.38 \mathrm{cpd}$ (period range 2.6-4.6 day) and computing the cross correlation function. The period is the time interval between adjacent peaks. The zonal wavenumber is estimated from the phase differences while the vertical wavelength is estimated from the phase lag of zonal winds between 86 and $94 \mathrm{~km}$ altitude at Pontianak. Peak amplitudes are about $25 \mathrm{~m} \mathrm{~s}^{-1}$, compared with 30-day mean values of $10-15 \mathrm{~m} \mathrm{~s}^{-1}$.

\section{Discussion and Conclusions}

MF radar data obtained at Christmas Island and Pontianak, which are located on the equator and separated by about 


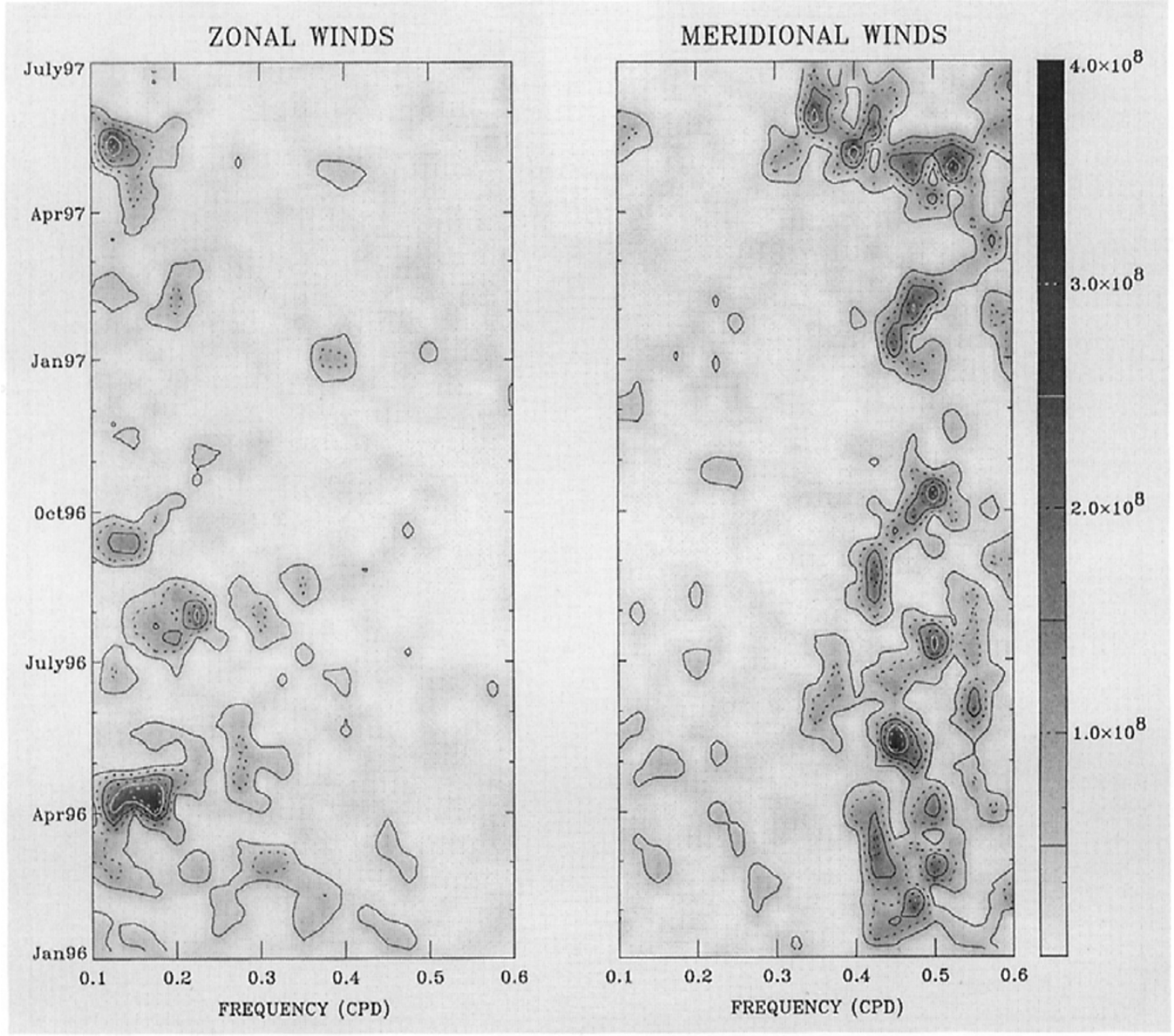

Fig. 5. Moving-window power spectra of zonal (left) and meridional (right) for Pontianak for the period November 1995 to August 1997.

Table 1. Properties of 3.5-day Kelvin waves inferred from harmonic fits to zonal winds in two-month intervals. The values in brackets indicate the zonal wavenumber due to aliasing

\begin{tabular}{lccccc}
\hline Observation period & Mar-Apr 96 & May-Jul 96 & Aug-Oct 96 & Nov-Dec 96 & Mean \\
Wave period & $3.3 \mathrm{~d}$ & $3.5 \mathrm{~d}$ & $3.5 \mathrm{~d}$ & $3.7 \mathrm{~d}$ & $3.5 \mathrm{~d}$ \\
Zonal wave-number & +0.7 & +1.1 & +0.7 & +0.8 & +1 \\
& $(-3.1)$ & $(-2.7)$ & $(-3.1)$ & $(-3.0)$ & \\
Amplitude & $25 \mathrm{~m} / \mathrm{s}$ & $30 \mathrm{~m} / \mathrm{s}$ & $25 \mathrm{~m} / \mathrm{s}$ & $20 \mathrm{~m} / \mathrm{s}$ & $25 \mathrm{~m} / \mathrm{s}$ \\
Vertical wavelength & $76 \mathrm{~km}$ & $80 \mathrm{~km}$ & $53 \mathrm{~km}$ & $88 \mathrm{~km}$ & $75 \mathrm{~km}$ \\
\hline
\end{tabular}

$94^{\circ}$ in longitude, are used to explore the characteristics of planetary-scale waves in the equatorial MLT region (78-98 $\mathrm{km})$. A number of discrete long-period oscillations in the zonal wind and meridional winds are found to have common temporal behavior. Spectral analyses show that the power spectral densities are very similar at all frequencies at both locations, with narrow spectral peaks occurring at tidal periods and broader peaks near two days in the meridional component and near 6.5 and 3.5 days in the zonal component. Moving-window spectral analyses showed that the quasi-2day wave is a prominent and almost continuous feature of the meridional wind component in the equatorial mesosphere, in agreement with earlier studies. The 6.5 and 3.5 day waves are more transient in their behavior, with bursts of oscillations lasting for $4-5$ cycles. The largest amplitudes occur near the equinoxes. Cross-spectral and harmonic analyses show that the waves propagate in opposite directions in the zonal direction. This suggests that the waves are of different types and have different origins.

\subsection{The 6.5-day wave}

The 6.5 day wave was found to have a long vertical wavelength ( $\gtrsim 65 \mathrm{~km}$ ) and that oscillations at Christmas Island lead those at Pontianak by about $90^{\circ}$, consistent with a westward propagating zonal wavenumber-1 planetary wave. In 

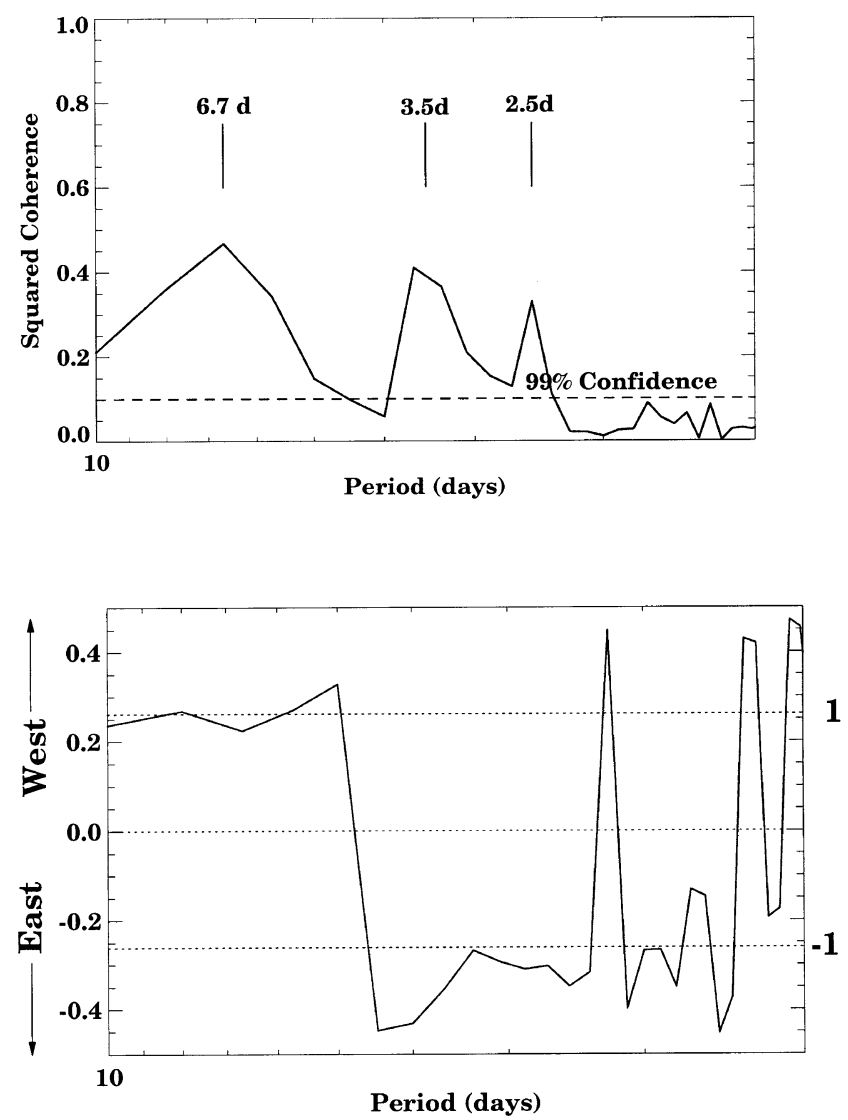

Fig. 6. Squared coherence (top) and cross-spectral phase (bottom) between zonal winds measured at Pontianak and Christmas Island. The period range is from 1.1 to 10 days

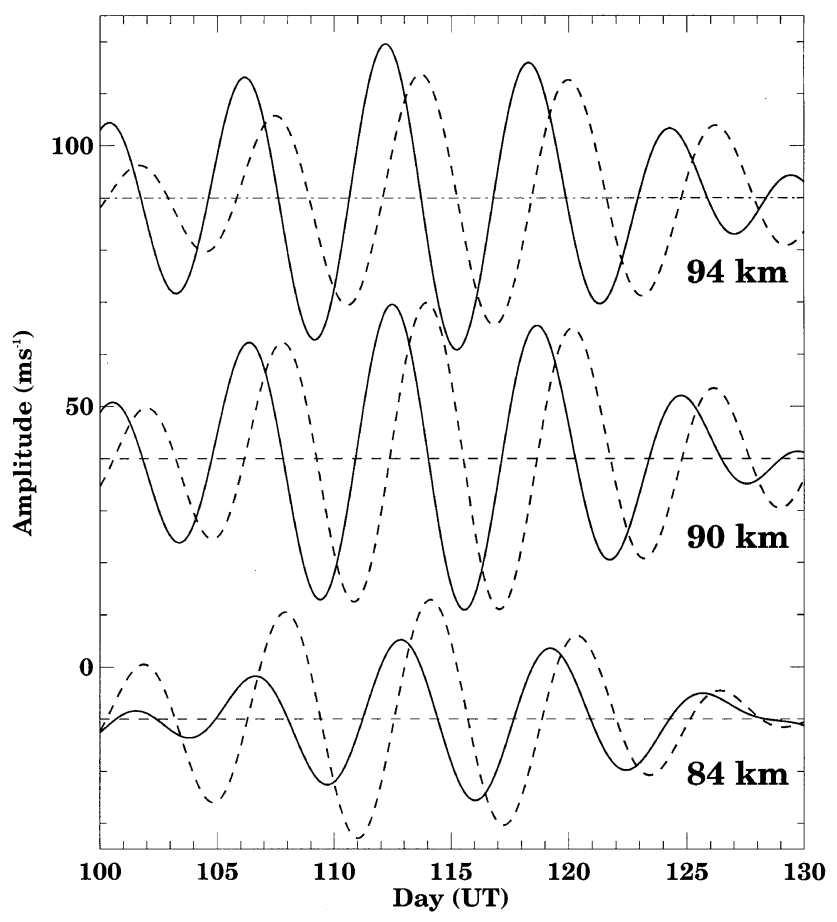

Fig. 7. Hourly-average zonal winds measured at Christmas Island (solid) and Pontianak (dashed) at heights of 84, 90 and $94 \mathrm{~km}$ during the period 9 April to 9 May 1996. The time series are bandpassed with a filter centered on 6.5 days.
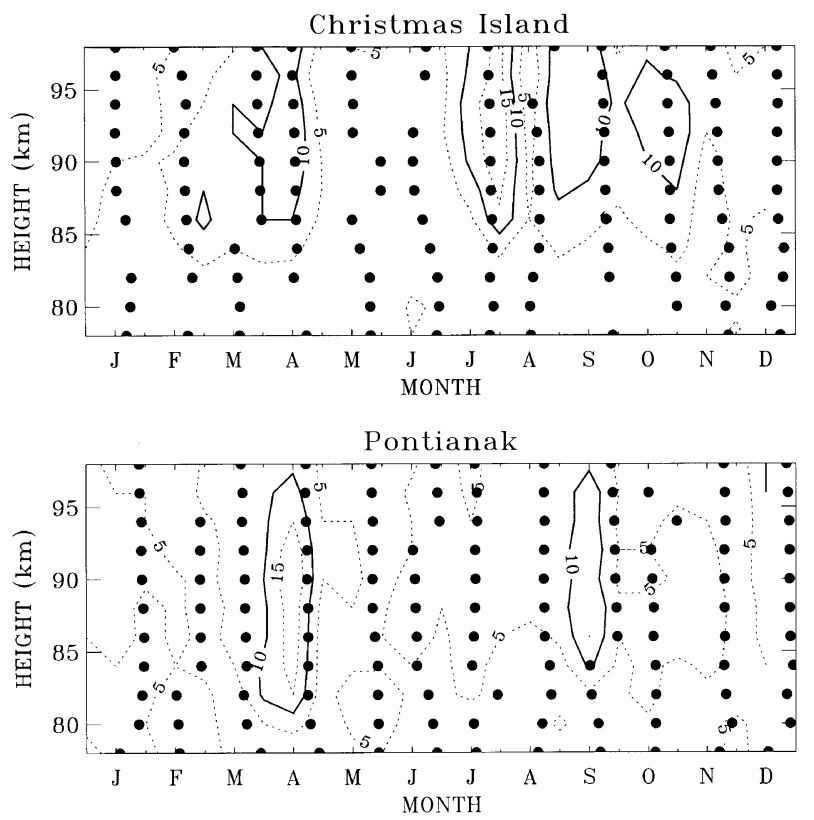

Fig. 8. Time-height cross section of zonal wind amplitudes and phases obtained from fits of a 6.5-day sinusoid to data at Christmas Island (top) and Pontianak (bottom) during 1996. Estimates are for 30 day intervals slid by 15 days. Filled circles denote time of maximum eastward wind.
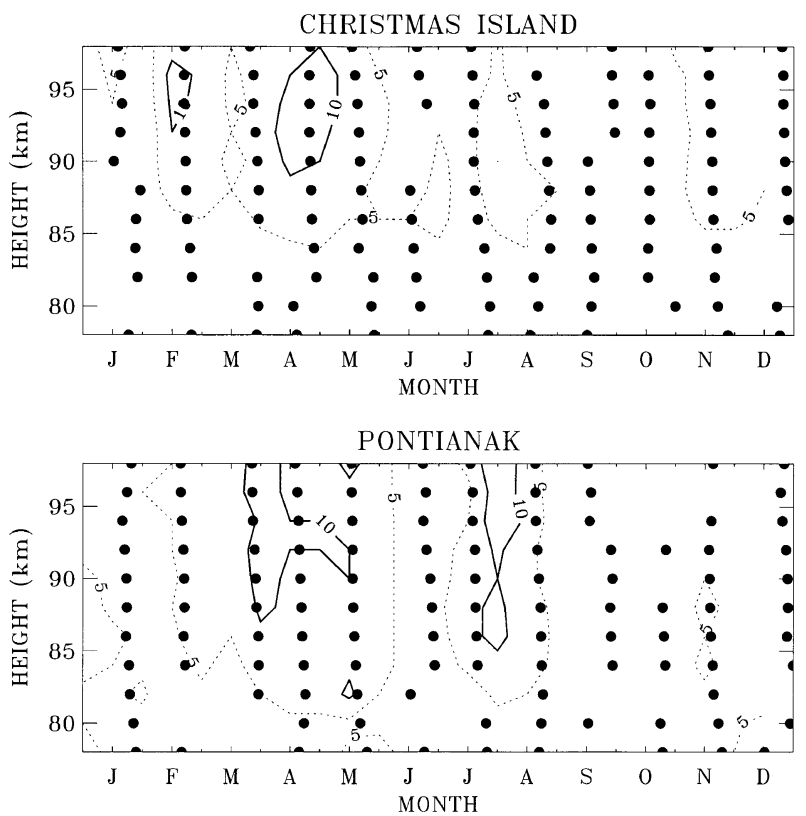

Fig. 9. As for Fig. 7, but for the 3.5-day wave.

previous studies using only Christmas Island data the 6.5day wave was identified as a fast Kelvin wave (Vincent and Lesicar, 1991; Vincent, 1993). This interpretation was based on the fact that the oscillations occur predominately in the zonal wind component, a key characteristic of Kelvin waves, and that no westward-propagating normal modes have periods near 6-7 days. Furthermore rocket and satellite observations had found significant $\sim 7$-day Kelvin wave activity in the equatorial stratosphere (Hirota, 1978, 1979; Hitchman 
and Leovy, 1986; Canziani et al., 1995). Maximum wave activity at the stratopause was reported to occur when the background winds were westward, that is opposite to the eastward propagating waves. Similarly, maximum wave activity of the 6.5-day wave at the mesopause is found to occur at the equinoxes when the background flow is westward.

One problem with the Kelvin wave interpretation is that, as discussed above, the vertical wavelength of the 6.5-day wave is observed to be greater than $65 \mathrm{~km}$. The dispersion relation for Kelvin waves is the same as large scale two-dimensional gravity waves (Andrews et al., 1987) viz:

$$
m=\sqrt{\frac{N^{2} k^{2}}{\hat{\omega}^{2}}-\frac{1}{4 H^{2}}}
$$

where $N$ is the Väisälä-Brunt frequency, $m$ and $k$ are, respectively, the vertical and horizontal wavenumbers, $\hat{\omega}$ is the intrinsic frequency and $H$ is the scale height. Zonal wave-1 fast Kelvin waves have intrinsic phase speeds $(\hat{\omega} / k)$ of less than $100 \mathrm{~m} \mathrm{~s}^{-1}$, which, from (3), means vertical wavelengths $(2 \pi / m)$ shorter than $25-30 \mathrm{~km}$. Higher zonal wavenumber waves would have even shorter wavelengths. The long vertical wavelength and the phase relation between Christmas Island and Pontianak indicating westward propagation taken together mean that an explanation other than Kelvin waves is required.

Meyer and Forbes (1997) discuss satellite and radar observations made in August-September 1993 at mid latitudes in the 80-100 km height region which showed a westward propagating wave with a period somewhat greater than 6days. This had been interpreted as a Doppler-shifted 5-day normal mode (Wu et al., 1994), although the 5-day wave is known to be insensitive to the state of the mean wind. Meyer and Forbes (1997) showed that this event is probably a manifestation of an unstable mode driven by shear of the zonal mesospheric jet located near $60^{\circ} \mathrm{N}$. The 6.5 day wave resembles a Kelvin wave in that there is little or no signature in the meridional wind at the equator, but it has a much larger vertical wavelength.

Our observations are consistent with the characteristics of the 6.5-day wave described by Meyer and Forbes (1997). Furthermore, observations of strong 6.5-day wave events in April as well as September suggest that it is a common feature of the equinoctial MLT region. An analysis similar to that described by Meyer and Forbes (1997) indicates that the middle atmosphere wind field in April is conducive to the generation of the wave by instabilities and there is a strong response to in situ momentum forcing at high latitudes in the southern hemisphere (C. Meyer, Personal Communication, 1998). These results show that instabilities are a common feature of the equinoctial middle atmosphere wind fields.

One final point, is that there appears be a small longitudinal variation in wave amplitude. Both Fig. 2 and Fig. 8 suggest slightly larger amplitudes for fluctuations near 6.5 day over Christmas Island than over Pontianak. This needs to be confirmed by further study, but may indicate stronger dissipation over Indonesia due to strong gravity wave activity in this region.

\subsection{The 3.5-day wave}

In contrast to the 6.5-day wave, the characteristics of 3.5day period waves observed at Christmas Island and Pontianak are consistent with these being manifestations of Kelvin waves. Ultrafast wavenumber-1 Kelvin waves have intrinsic phase speeds $\sim 150 \mathrm{~m} \mathrm{~s}^{-1}$, or vertical wavelengths of $\sim 50$ $\mathrm{km}$, which is consistent with our observations. Our results are also consistent with observations of 3-day Kelvin waves made with the High Resolution Doppler Instrument (HRDI) instrument on the UARS satellite (Lieberman and Riggin, 1997) and with previous equatorial radar observations (Riggin et al., 1997). Using 10-day sequences of observations Lieberman and Riggin (1997) report eastward propagating signatures which maximize near the equator in wavenumbers 1, 2, and 3 in the zonal wind field with periods near 3 days. Riggin et al. (1997), using a 9-month sequence of MF radar wind data from Christmas Island and meteor radar data from Jakarta taken in 1993, found a high degree of coherence between the two sites at periods near 3 days. The long vertical wavelength suggested that it was predominantly zonal wavenumber 1 . The nineteen month sequence of observations discussed here allow us to update these studies.

During July, the radar amplitudes are fairly consistent with the HRDI amplitudes. Comparisons with HRDI derived phases for June/July, the observed phases agree well throughout much of the vertical radar range, generally decreasing systematically with increasing altitude. At Christmas Island, the phase agreement is quite good in the 80-90 km layer where upward energy propagation is observed; however, radar amplitudes are weaker than HRDI amplitudes, a tendency that has been documented by Burrage et al. (1996a). HRDI phases are generally consistent with Pontianak and Christmas Island below $90 \mathrm{~km}$ but deviate substantially above that level.

An interesting feature of the contour plots in Fig. 9 is that amplitudes at Pontianak are often different to those observed at Christmas Island. In months when the amplitudes are largest (March/May and July/August) the amplitudes at Pontianak are larger than at Christmas Island by a ratio that varies between 1.25 and 1.4 for heights between 80 and 98 $\mathrm{km}$. This supports the findings of Riggin et al. (1997) who compared Jakarta meteor radar observations with Christmas Island MF radar observations. Riggin et al. (1997) were not sure whether the difference was due to instrumental differences or to source effects. The radars used in this study are identical which shows that source effects are the cause of the longitudinal differences. Pontianak and Jakarta, located as they are in the strong convection region of the Maritime Continent, are close to the source of Kelvin waves. Radiosonde observations made in Indonesia of 3.5-day Kelvin waves near their generating regions in the lower atmosphere and comparisons with Jakarta meteor radar observations in the mesosphere are discussed in Yoshida et al. (1998).

The amplitude growth of the 3.5-day wave with height is less than might be expected if the waves were propagating without dissipation. Dissipating waves exert a body force on the atmosphere through the convergence of the vertical component of zonal momentum flux, given by $\rho \overline{u^{\prime} w^{\prime}}$ (Andrews et al., 1987), where $\rho$ is atmospheric density and $u^{\prime}$ and $w^{\prime}$ are the zonal and vertical perturbation velocities, respectively. Since vertical velocities are not measured using the MF radars we follow Riggin et al. (1997) and use the polarization relations and dispersion relation (3) to recast $w^{\prime}$ in 
Table 2. Average of zonal accelerations $\left(\mathrm{m} \mathrm{s}^{-1}\right.$ day $\left.{ }^{-1}\right)$ for 3.5-day wave in 1996 . The values in brackets refer to January-September 1993 for Jakarta and Christmas Island (Riggin et al., 1997).

\begin{tabular}{ccccc}
\hline Height $(\mathrm{km})$ & \multicolumn{2}{c}{ Pontianak } & \multicolumn{2}{c}{ Christmas Island } \\
\hline \multirow{2}{*}{$86-90$} & Jan-Sept & Jan-Dec & Jan-Sept & Jan-Dec \\
& $0.18 \pm 0.05$ & $0.15 \pm 0.06$ & $-0.06 \pm 0.01$ & $-0.06 \pm 0.01$ \\
\multirow{2}{*}{$90-94$} & $(0.18 \pm 0.05)$ & & $(0.30 \pm 0.03)$ & \\
& $0.48 \pm 0.06$ & $0.44 \pm 0.06$ & $0.21 \pm 0.04$ & $0.19 \pm 0.14$ \\
& $(0.54 \pm 0.08)$ & & $(0.29 \pm 0.04)$ & \\
\hline
\end{tabular}

terms of $u^{\prime}$ so the vertical momentum flux becomes

$$
P=\frac{1}{2} \rho \overline{u^{\prime 2}} \mathcal{R}\left[-\frac{k}{\left(m^{2}+\frac{1}{4 H^{2}}\right)}\left(m-\frac{i}{2 H}\right)\right] .
$$

Vertical profiles of $P$ were computed from the 30-day average amplitude fits, with estimates of $m$ made from the phase profiles; a value of $k$ appropriate for a zonal wavenumber-1 Kelvin wave was assumed. The body force per unit mass is then $a_{x}=-\rho^{-1}(\partial P / \partial z)$. Values of $P$ were computed at $2-$ $\mathrm{km}$ height intervals and then smoothed by fitting a third-order polynomial before computing the vertical derivative.

Estimates of $a_{x}$ as a function of time are shown in Fig. 10 for Christmas Island and Pontianak in the two height intervals of $86-90 \mathrm{~km}$ and $90-94 \mathrm{~km}$. There are a number of interesting features. In the lower height range the values at Christmas Island are consistently negative whereas at Pontianak the values are positive, except in the last part of 1996. Above $90 \mathrm{~km}$ the values of $a_{x}$ are positive at both locations, but the values at Pontianak tend to be larger in magnitude, especially in July/August. Annual average values for the two height intervals are given in Table 2, where they are also compared with the nine-month averages from Riggin et al. (1997) using Jakarta and Christmas Island data between January and September 1993.

There is rather good agreement between the estimates of $a_{x}$ made here and those reported in Riggin et al. (1997), especially above $90 \mathrm{~km}$. It is noteworthy that the 12-month averages for $a_{x}$ are somewhat smaller than the 9-month averages and that the values for 1993 tend to be a little larger than for 1996. The latter feature may indicate interannual variability, but it is probable that somewhat different data processing techniques also influence the results. Riggin et al. (1997) used shorter fitting intervals (12.8 days) in their analysis than the 30-day fits that were used here. As Table 1 shows, the peak amplitudes observed in 1996 are often twice as large as the 30-day average values, so we if had used shorter fitting intervals the inferred fluxes would have been larger. What is important is that both studies show that the Kelvin waves have larger amplitudes in the Asian region than in the central Pacific and the wave drag exerted on the zonal flow is larger in this region. The longitudinal variations in the Kelvin-wave drag may account, in part, for the longitudinal variations in the amplitude of the mesospheric semiannual oscillation observed from HRDI measurements (Smith, 1997).

Comparing the time sequence of accelerations (Fig. 10)
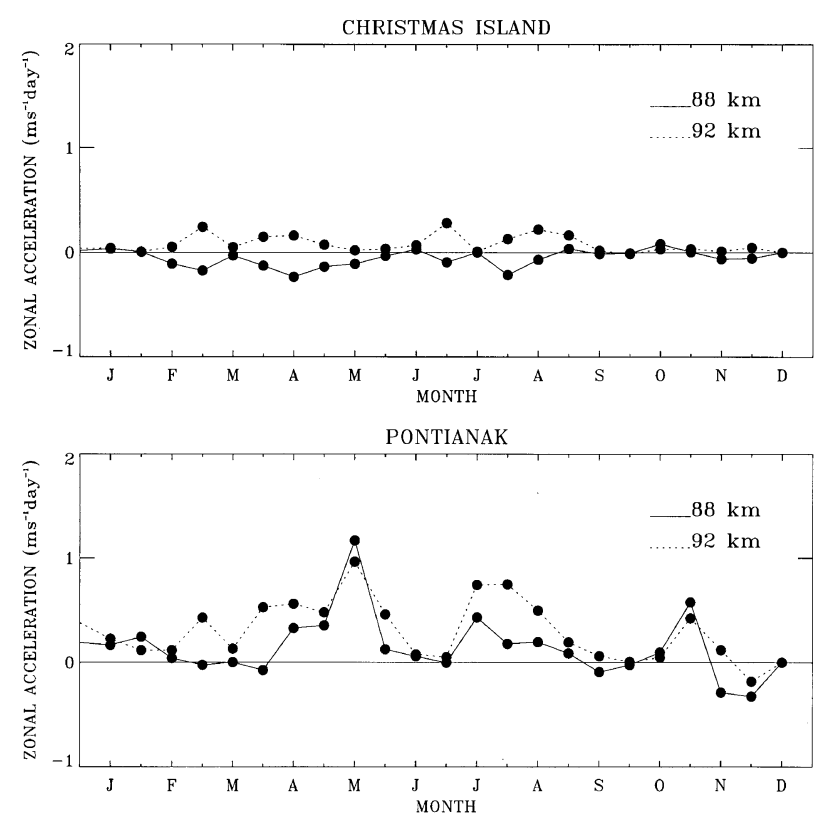

Fig. 10. Time series of zonal body force estimates for Christmas Island (top) and Pontianak (bottom) for the 3.5-day wave. The solid (dashed) line shows values in the 86-90 (90-94) km height range.

with the evolution of the 86-km zonal winds shown in Fig. 1, it seems that the large positive values of $a_{x}$ in May 1996 at Pontianak coincide with the reversal of the zonal flow from westward to eastward. Similarly, the positive $a_{x}$ observed in late October may account for the positive acceleration in the zonal flow at that time. In contrast, zonal winds are reversing from eastward to westward in July/August, when positive Kelvin-wave accelerations are observed. Overall, the results are ambiguous. While they suggest that Kelvin waves play a role in the mesospheric momentum budget, that role is small. Lieberman and Riggin (1997) concluded that 3-day Kelvin waves are an important source of eastward momentum in the lower thermosphere near $100 \mathrm{~km}$, but that their influence is significantly smaller in the MSAO region near $85 \mathrm{~km}$. It is worth noting that Hitchman and Leovy (1988) concluded from an analysis of daily-mapped stratospheric temperatures that Kelvin waves made a significant but decreasing contribution to the zonal momentum budget above $\sim 30 \mathrm{~km}$, while the influence of smaller scale gravity waves increased. The contribution of gravity waves to the momentum budget of the equatorial mesosphere has yet to be fully explored. 
Acknowledgments. Helpful discussions with C. Meyer and J. Forbes are gratefully acknowledged. Operation of the Christmas Island radar is supported by the Australian Research Council. Support from grants 09044080 and 07044082 , from the Ministry of Education, Science, Sports and culture of Japan from The Mitsubishi Foundation is also acknowledged.

\section{References}

Andrews, D. G., J. R. Holton, and C. B. Leovy, Middle Atmospheric Dynamics, 489 pp., Academic Press, Orlando, 1987.

Avery, S. K., J. P. Avery, T. A. Valentic, S. E. Palo, M. J. Leary, and R. L. Obert, A new meteor echo detection and collection system: Christmas Island mesospheric measurements, Radio Sci., 25, 657-669, 1990.

Briggs, B. H., The analysis of spaced sensor records, in Handbook for Map, 13, edited by R. A. Vincent, pp. 166-186, 1984.

Burrage, M. D., D. A. Gell, P. B. Hays, A. R. Marshall, D. A. Ortland, W. R. Skinner, S. J. Franke, D. C. Fritts, P. Hoffman, A. H. Manson, C. McLandress, R. Nieciejewski, F. J. Schmidlin, G. G. Shepherd, W. Singer, T. Tsuda, and R. A. Vincent, Validation of mesospheric and lower thermospheric winds from the high resolution Doppler imager, J. Geophys. Res., 101, 10,365-10,392, 1996a.

Burrage, M. D., R. A. Vincent, H. G. Mayr, W. R. Skinner, N. F. Arnold, and P. B. Hays, Long-term variability in the equatorial mesosphere and lower thermosphere zonal wind, J. Geophys. Res., 101, 12,847-12,854, 1996 b.

Canziani, P, O., J. R. Holton, E. F. Fishbein, and L. Froideveaux, Equatorial Kelvin wave variability during 1992 and 1993, J. Geophy. Res., 100, 5193-5202, 1995.

Conner, L. N. and S. K. Avery, A three year gravity wave climatology of the mesosphere and lower thermosphere over Kauai, J. Geophys. Res., 101, 4065-4077, 1996.

Dunkerton, T. J., A Theory of the mesopause semiannual oscillation, $J$. Atmos. Sci., 39, 2681-2690, 1982.

Eckermann, S. D. and R. A. Vincent, First observations of intraseasonal oscillations in the equatorial mesosphere and lower thermosphere, Geophys. Res. Lett., 21, 265-268, 1994.

Eckermann, S. D., D. K. Rajopadhyaya, and R. A. Vincent, Intraseasonal wind variability in the equatorial mesosphere and lower thermosphere: Long term observations for the central Pacific, J. Atmos. Terr. Phys., 59 603-627, 1997.

Fritts, D. C. and T. E. VanZandt, Spectral estimates of gravity wave energy and momentum fluxes. Part I: Energy dissipation, acceleration, and constraints, J. Atmos. Sci., 50, 3685-3694, 1993.

Garcia, R. R., T. J. Dunkerton, R. S. Lieberman, and R. A. Vincent, Climatology of the semiannual oscillation of the tropical middle atmosphere, J. Geophys. Res., 102, 26,019-26,032, 1997.

Hamilton, K. P., Rocketsonde observations of the mesospheric semiannual oscillation at Kwajalein, Atmos-Oceans., 20, 281-286, 1982.

Harris, T. J. and R. A. Vincent, The Quasi-Two-day wave Observed in the Equatorial Middle atmosphere, J. Geophys. Res., 98, 10,481-10,490, 1993.

Hirota, I., Equatorial waves in the upper stratosphere and mesosphere in relation to the semiannual oscillation of the zonal wind, J. Atmos. Sci., 35, 714-722, 1978.

Hirota, I., Kelvin waves in the equatorial middle atmosphere observed by the Nimbus 5 SCR, J. Atmos. Sci., 36, 217-222, 1979.

Hitchman, M. H. and C. B. Leovy, Evolution of the zonal mean state in the equatorial middle atmosphere during October 1978-May 1979, J. Atmos. Sci., 43, 1253-1267, 1986.

Hitchman, M. H. and C. B. Leovy, Estimation of the Kelvin wave contribution to the semiannual oscillation, J. Atmos. Sci., 45, 1462-1475, 1988.

Isler, J. R. and D. C. Fritts, gravity wave variability and the interaction with the low frequency motions in the lower mesosphere and thermosphere over Hawaii, J. Atmos. Sci., 53, 37-38, 1996.

Lieberman, R. S., Intraseasonal variability of high-resolution Doppler imager winds in the equatorial mesosphere and lower thermosphere, J. Geophys. Res., 103, 11,221-11,228, 1998.

Lieberman, R. S., M. D. Burrage, D. A. Gell, P. B. Hays, A. R. Marshall, D. A. Ortland, W. R. Skinner, D. Wu, R. A. Vincent, and S. J. Frank,
Zonal mean winds in the equatorial mesosphere and lower thermosphere observed by the high resolution Doppler imager, Geophys. Res. Lett., 20, 2849-2852, 1993.

Lieberman, R. S. and D. Riggin, High resolution Doppler imager observations of Kelvin waves in the equatorial mesosphere and lower thermosphere, J. Geophys. Res., 102, 26,117-26,129, 1997.

Liebmann, B. and H. H. Hendon, Synoptic-scale disturbances near equator, J. Atmos. Sci., 47, 1463-1479, 1990.

McLandress, C., G. G. Shepherd, B. H. Solhiem, M. D. Burrage, P. B. Hays, and W. R. Skinner, Combined Mesosphere/Thermosphere winds using WINDII and HRDI data from the Upper Atmospheric Research Satellite, J. Geophys. Res., 101, 10,441-10,453, 1996.

Meyer, C. K. and J. M. Forbes, A 6.5-day westward propagating planetary wave: origin and its characteristics, J. Geophys. Res., 102, 26,17326,178, 1997

Palo, S. E. and S. K. Avery, Mean winds and the semiannual oscillations in the mesosphere and lower thermosphere at the Christmas island, $J$. Geophys. Res., 98, 20,385-20,400, 1993.

Palo, S. E. and S. K. Avery, Observations of the quasi-two-day wave in the middle and lower atmosphere over Christmas Island, J. Geophys. Res., 101, 12,833-12,846, 1996.

Palo, S. E., M. E. Hagan, C. E. Meek, R. A. Vincent, M. D. Burrage, C. McLandress, S. J. Franke, W. Ward, R. R. Clark, P. Hofman, R. Johnson, D. Kuerschner, A. H. Manson, D. Murphy, T. Nakamura, Yu. I. Potnyagin, J. E. Salah, R. Schminder, W. Singer, T. Tsuda, T. S. Virdi, and Q. Zhou, An intercomparison between GSWM, UARS and ground-based radar observations: A case study in January 1993, Ann. Geophys., 15, 1123 1141, 1997

Press, W. H., S. A. Teukolsky, W. T. Vetterling, and B. P. Flannery, Numerical Recipes in C: The Art of Scientific Computing, 2nd Ed., 994 pp. Cambridge University Press, Cambridge, 1992.

Riggin, D., D. C. Fritts, T. Tsuda, T. Nakamura, and R. A. Vincent, Radar observations of a 3-day Kelvin wave in the equatorial mesosphere, $J$. Geophys. Res., 102, 26,141-26,157, 1997.

Salby, M . L., The 2-day wave in the middle atmosphere: Observations and theory, J. Geophys. Res., 86, 9654-9664, 1981.

Salby, M. L., Survey of planetary-scale traveling waves: The state of theory and observations, Rev. Geophys. Space Phys., 22, 209-236, 1984.

Smith, A. K., Longitudinal variability of the mesopause SAO, Geophys. Res. Lett., 24, 1991-1994, 1997.

Tsuda, T., S. Fukao, M. Yamamoto, T. Nakamura, M. D. Yamanaka, T. Adachi, H. Hashiguchi, N. Fujioka, M. Tsutsumi, S. Kato, S. W. B. Harijono, T. Sribimawati, B. P. Sitorus, R. B. Yahya, M. Karmini, F. Renggono, B. L. Parapat, W. Djojonegoro, P. Mardio, N. Adikusumah, H. T. Endi, and H. Wirosumarto, A preliminary report on observations of equatorial dynamics in Indonesia with radars and radiosondes, J. Meteor Soc. Japan., 73, 393-406, 1995.

Vincent, R. A., Long-period motions in the equatorial mesosphere, J. Atmos. Terr. Phys., 55, 1067-1080, 1993.

Vincent, R. A. and D. Lesicar, Dynamics of the equatorial mesosphere: First results with a new generation partial reflection radar, Geophys. Res. Lett., 18, 825-828, 1991 .

Vincent, R. A., S. Kovalam, D. C. Fritts, and J. R. Isler, Long-term MF radar observations of solar tides in the low-latitude mesosphere: Interannual variability and comparisons with the GSWM, J. Geophys. Res., 103, 8667-8683, 1998

Wu, D. L., P. B. Hays, W. R. Skinner, A. R. Marshall, M. D. Burrage, R. S. Lieberman, and D. A. Ortland, Observations of the quasi 2-day wave from the High Resolution Doppler Imager on UARS, Geophys. Res. Lett. 20, 2853-2856, 1993.

Wu, D. L., P. B. Hays, and W. R. Skinner, Observations of the 5-day waves in the mesosphere and lower thermosphere, Geophys. Res. Lett., 21, 2733 2736, 1994

Yoshida, S., T. Tsuda, A. Shimizu, and T. Nakamura, Seasonal variations of 3.0 3.8-day ultra-fast Kelvin waves observed with a meteor radar and radiosondes in Indonesia, Earth, Planet. Sci., 1998 (submitted).

S. Kovalam (e-mail: skovalam@physics.adelaide.edu.au), R. A Vincent, I. M. Reid, T. Tsuda, T. Nakamura, K. Ohnishi, A. Nuryanto, and $\mathrm{H}$. Wiryosumarto 